\title{
RESEARCH
}

Open Access

\section{Prevalence and predictors of aortic root abscess among patients with left-sided infective endocarditis: a cross-sectional comparative study}

\author{
Kareem Mahmoud ${ }^{*}$ (D), Tarek Hammouda, Hossam Kandil and Marwa Mashaal
}

\begin{abstract}
Background: Aortic root abscess (ARA) is a major complication of infective endocarditis that is associated with increased morbidity and mortality. Limited data are present about patient characteristics and outcomes in this lethal disease. We aimed to study the clinical and echocardiographic characteristics of patients with ARA compared to patients with left-sided infective endocarditis without ARA. We included patients with a definite diagnosis of leftsided infective endocarditis according to modified Duke's criteria. The patients were classified into two groups according to the presence of ARA (ARA and NO-ARA groups). All the patients were studied regarding their demographic data, clinical characteristics, laboratory and imaging data, and complications.

Results: We included 285 patients with left-sided infective endocarditis. The incidence of ARA was $21.4 \%$ (61 patients). Underlying heart disease, mechanical prosthesis, bicuspid aortic valve, and prior IE were significantly higher in ARA. The level of CRP was higher in ARA $(p=0.03)$. ARA group showed more aortic valve vegetations (73.8\% vs. $37.1 \%, p<0.001)$, more aortic paravalvular leakage ( $26.7 \%$ vs. $4.5 \%, p<0.001)$, and less mitral valve vegetations $(21.3 \%$ vs. $68.8 \%, p<0.001)$. Logistic regression analysis showed that the odds of ARA increased in the following conditions: aortic paravalvular leak (OR 3.9, 95\% Cl 1.2-13, $p=0.03)$, mechanical prosthesis (OR 3.6, 95\% Cl 1.5-8.7, $p=0.005)$, aortic valve vegetations (OR 3.0, 95\% Cl 1.2-8.0, $p=0.02)$, and undetected organism (OR 2.3, $95 \% \mathrm{Cl} 1.1-4.6, p=0.02$ ), while the odds of ARA decreased with mitral valve vegetations (OR $0.2,95 \% \mathrm{Cl} 0.08-0.5, p$ $=0.001)$. We did not find a difference between both groups regarding the incidence of major complications, including in-hospital mortality.

Conclusion: In our study, ARA occurred in one fifth of patients with left-sided IE. Patients with mechanical prosthesis, aortic paravalvular leakage, aortic vegetations, and undetected organisms had higher odds of ARA, while patients with mitral vegetations had lower odds of ARA.
\end{abstract}

Keywords: Aortic root abscess, Infective endocarditis, Paravalvular leakage

\footnotetext{
*Correspondence: dr.kareem215@yahoo.com
}

Cairo University, Cairo, Egypt

\section{Springer Open}

(c) The Author(s). 2020 Open Access This article is licensed under a Creative Commons Attribution 4.0 International License which permits use, sharing, adaptation, distribution and reproduction in any medium or format, as long as you give appropriate credit to the original author(s) and the source, provide a link to the Creative Commons licence, and indicate if changes were made. The images or other third party material in this article are included in the article's Creative Commons licence, unless indicated otherwise in a credit line to the material. If material is not included in the article's Creative Commons licence and your intended use is not permitted by statutory regulation or exceeds the permitted use, you will need to obtain permission directly from the copyright holder. To view a copy of this licence, visit http://creativecommons.org/licenses/by/4.0/. 


\section{Background}

Infective endocarditis (IE) is a deadly disease with high mortality rates and high rates of complications [1]. Given the relatively low incidence of the disease, until recently, guidelines relied on expert opinion rather than controlled trials [2]. The majority of studies in the field of infective endocarditis were observational, with a limited number of randomized-controlled trials and meta-analyses [3-5].

Periannular extension of the infection can occur, causing periannular abscesses. Aortic root abscess has been found in up to $46 \%$ of aortic valve IE cases [6]. The incidence of infective endocarditis and aortic root abscess usually vary among different countries. Antibiotics alone may occasionally sterilize an abscess cavity. However, without surgical intervention, many patients die of congestive heart failure, sepsis, or both. Moreover, taking a full course of the appropriate antibiotic to achieve a healed status is not always possible, exposing patients to the risk of an aggressive surgical approach during the active phase $[7,8]$.

Few case series described the worldwide experience in such complication, pointing out the possible predictors, clinical course, and results of various management approaches $[6,9]$. Our study aimed to determine the prevalence, clinical and echocardiographic predictors of aortic root abscess in patients with left-sided infective endocarditis.

\section{Methods}

\section{Subjects}

This study was a cross-sectional comparative study that included patients with a definite diagnosis of left-sided infective endocarditis according to modified Duke's criteria [10]. The patients were recruited as part of the infective endocarditis registry from January 2014 to February 2019. The infective endocarditis team consists of cardiologists, cardiothoracic surgeons, echocardiographers, microbiologists, and pathologists. We obtained written informed consent from all patients enrolled in the study to collect their data. The institutional ethics review committee approved the study.

We included 285 patients with left-sided infective endocarditis and divided them into two groups:

Aortic root abscess (ARA) group: included patients with left-sided infective endocarditis complicated with aortic root abscess (61 patients).

No aortic root abscess (NO-ARA) group: included patients with left-sided infective endocarditis not complicated with aortic root abscess (225 patients).

\section{Methods}

All study population had the following diagnostic workup:

History: age, gender, underlying cardiac conditions, comorbidities (e.g., hypertension, diabetes mellitus, liver and kidney diseases, autoimmune disease, and chronic steroid use), symptoms related to infective endocarditis, and its duration.

Clinical examination: vital signs, signs of heart failure, and findings related to infective endocarditis (e.g., clubbing, Roth spot, splenomegaly, neurological affection, and cutaneous manifestations).

Laboratory workup: hemoglobin, total leukocytic count, serum creatinine, and CRP.

Blood culture and sensitivity according to the recent guidelines [11].

Serology for Aspergillus, Brucella, Coxiella, Listeria, Bartonella.

NB. We reported the causative microorganisms according to the results of blood cultures or serology. The undetected organism was the condition when both blood cultures and serology were negative.

Transthoracic echocardiography (TTE) was done for all patients as an initial investigation in cases of infective endocarditis within 24-48 h of admission [12].

Transesophageal echocardiography (TEE) was done for the diagnosis of IE and the detection of local complications. Images were obtained using the Philips X7-2t ultrasound probe on the Philips IE33 (Philips Medical Systems, Andover, Massachusetts). Sedation was done using IV midazolam, given in an increment of 1-2 mg. The patients were asked to fast for $6 \mathrm{~h}$. Standard midesophageal, transgastric, and upper esophageal views were obtained as recommended by the American Society of Echocardiography guidelines for performing TEE examination [13]. Vegetation was defined as an oscillating or non-oscillating intracardiac mass on a valve or other endocardial structures. Abscess was identified as a thickened, non-homogeneous echodense or echolucent perivalvular space $[12,14]$. Figure 1 shows an example of the use of TEE in diagnosing ARA.

Abdominal ultrasonography was performed for all patients to evaluate the complications of infective endocarditis, as splenic infarctions and splenic abscess.

Duplex ultrasound or CT angiography: Either of these tests was done on clinical suspicion of peripheral embolization (e.g., symptoms of limb ischemia, absent pulsations).

CT brain, MRI brain, or CT cerebral angiography: Either of these tests was done for almost all cases as a standard practice as long as it is not interfering with the urgency of the surgery. This enabled us to detect intracranial complications, especially silent mycotic aneurysms.

In-hospital clinical major complications were defined as the presence of one of the following:

- In-hospital mortality

- Any clinically overt central nervous system event (embolic brain infarction, brain hemorrhage, transient ischemic attack, or meningitis) 

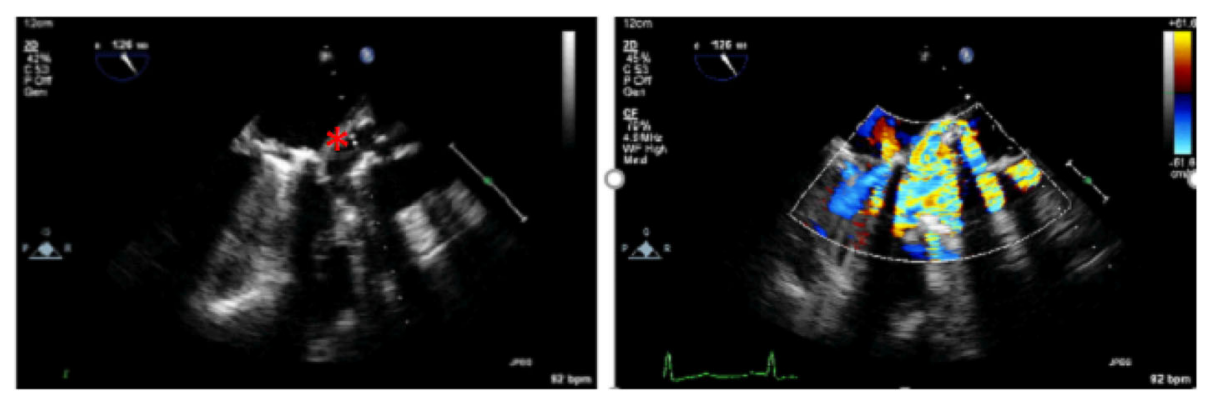

Fig. 1 TEE showing large aortic root abscess (ARA). The left image: ARA is seen at the posterior aspect of the aortic root as marked by *. The right image: considerable paravalvular leakage from the aorta to the left ventricular outflow tract

- Peripheral embolization to extremities or abdominal viscera

- Congestive heart failure NYHA classes III-IV

Sepsis: defined as life-threatening organ dysfunction caused by a dysregulated host response to infection with the following clinical criteria: suspected or documented infection and an acute increase of two or more SOFA (Sepsis-related Organ Failure Assessment) score points [15].

Acute kidney injury: defined as either a rise in serum creatinine by $0.3 \mathrm{mg} / \mathrm{dL}$ or more within $48 \mathrm{~h}$, a rise in serum creatinine to 1.5 times baseline or more within the last 7 days, or a decline in urine output to less than $0.5 \mathrm{~mL} / \mathrm{kg} / \mathrm{h}$ for $6 \mathrm{~h} \mathrm{[16]}$.

\section{Primary objectives}

To estimate the prevalence of aortic root abscess in patients with left-sided IE.

To assess the association between the clinical and echocardiographic data mentioned above and ARA in patients with left-side IE.

\section{Secondary endpoints}

To compare major in-hospital complications in patients with and without ARA.

\section{Statistical methods}

All data were analyzed using the SPSS version 24 statistical software and $\mathrm{R}$ statistical package version 3.5.1, with a two-tailed $p$ value $<0.05$ indicating statistical significance. Normally distributed numerical values were reported as mean \pm standard deviation (SD). For variables with a skewed distribution, data were expressed as a median and inter-quartile range. Qualitative variables were presented as counts and percentages. Comparisons of continuous data between groups were made using the two-sample $t$ test or the Mann-Whitney $U$ test as appropriate. The chi-square test or Fisher's test were used to make between-group comparisons as appropriate. Statistically significant variables on univariate analysis were entered in a stepwise multivariable logistic regression analysis to determine predictors of the abscess.

\section{Results}

Our study included 285 patients with left-sided infective endocarditis. There were 152 patients with aortic valve IE representing $53.3 \%$ of the total number of patients. ARA was detected in 61 patients representing $21.4 \%$ of the whole study population and $40.1 \%$ of aortic valve IE patients.

Table 1 shows the baseline demographic and underlying heart diseases of both groups. Male gender, prosthetic valve, congenital heart diseases (bicuspid aortic valve, subaortic membrane, and ventricular septal defects), and prior infective endocarditis were significantly higher in the ARA group. Regarding symptoms and physical signs, the NO-ARA group showed an increased incidence of clubbing compared with the ARA group ( $20 \%$ vs. $8.5 \%$ ). The rest of the symptoms and signs were not different between both groups, as shown in Fig. 2 .

The laboratory data of both groups are shown in Table 1 . We found that the CRP level was higher in the ARA group as compared with the NO-ARA group. The rest of the studied labs were not different between both groups.

Different microorganisms, as detected by blood cultures and serological tests, are shown in Fig. 3. There was a trend towards an increased incidence of undetected organisms in the ARA group as compared to the NO-ARA group ( $54.1 \%$ vs. $42.0 \%, p=0.09)$. Antibiotic use before the referral showed no statistically significant difference between both groups $(67.8 \%$ vs. $70.5 \%, p=0.69$ ).

Figure 4 shows the echocardiographic data of both groups. Overall, the vegetations were less seen in the ARA group. Reviewing the vegetations by site, the ARA group showed less mitral valve vegetations, considerably higher aortic valve vegetations, higher paravalvular leakage, and lower incidence of moderate to severe valvular regurgitant lesions. Mitral vegetations were detected in $58.5 \%$ of the whole study patients $(48.2 \%$ as isolated mitral vegetations and $10.3 \%$ as combined mitral and aortic vegetations). Isolated mitral vegetations were significantly less in the ARA 
Table 1 Demographic, clinical characteristics, and laboratory data of the patients with and without aortic root abscess, median \pm IQR or $N(\%)$

\begin{tabular}{|c|c|c|c|}
\hline & ARA $(N=61)$ & NO-ARA $(N=224)$ & $p$ value \\
\hline Age & $31(24,40.5)$ & $32(24,43)$ & 0.36 \\
\hline Male gender & $42(68.9 \%)$ & $122(54.5 \%)$ & 0.04 \\
\hline \multicolumn{4}{|l|}{ Underlying cardiac conditions } \\
\hline $\mathrm{RHD}$ & $27(45.0 \%)$ & $121(54.3 \%)$ & 0.20 \\
\hline Mechanical prosthesis & $31(50.8 \%)$ & $40(17.9 \%)$ & $<0.001$ \\
\hline Congenital heart disease & $11(18.3 \%)$ & $16(7.1 \%)$ & 0.009 \\
\hline Bicuspid aortic valve & $8(13.1 \%)$ & $9(4.0 \%)$ & 0.01 \\
\hline Prior IE & $8(13.3 \%)$ & $8(3.6 \%)$ & 0.008 \\
\hline Degenerative heart disease & $4(6.6 \%)$ & $23(10.4 \%)$ & 0.37 \\
\hline IV drug abuse & $0(0 \%)$ & $7(3.1 \%)$ & 0.35 \\
\hline Normal Heart & $1(1.6 \%)$ & $17(7.6 \%)$ & 0.14 \\
\hline \multicolumn{4}{|l|}{ Comorbidities } \\
\hline DM & $6(9.8 \%)$ & $15(6.7 \%)$ & 0.41 \\
\hline CKD & $4(6.6 \%)$ & $22(9.8 \%)$ & 0.43 \\
\hline Hemodialysis & $3(4.9 \%)$ & $8(3.6 \%)$ & 0.70 \\
\hline Chronic steroid use & $0(0 \%)$ & $12(5.4 \%)$ & 0.08 \\
\hline Chronic hepatic disease & $1(1.6 \%)$ & $10(4.5 \%)$ & 0.47 \\
\hline Collagen vascular disease & $0(0 \%)$ & $6(6.7 \%)$ & 0.35 \\
\hline \multicolumn{4}{|l|}{ Clinical manifestations } \\
\hline Duration of symptoms (Days) & $30(14,90)$ & $28(14,84)$ & 0.77 \\
\hline Temperature (Celsius) & $38(37,39)$ & $38(37.5,39)$ & 0.82 \\
\hline Heart rate (bpm) & $100(96,120)$ & $100(90,110)$ & 0.11 \\
\hline \multicolumn{4}{|l|}{ Laboratory data } \\
\hline Anemia & $52(94.5 \%)$ & 199 (93.9\%) & 0.999 \\
\hline Minimum Hemoglobin (gm/dL). & $8.9(7.5,10)$ & $9.0(7.7,10.2)$ & 0.61 \\
\hline Leukocytosis & $39(68.4 \%)$ & $137(65.2 \%)$ & 0.65 \\
\hline $\operatorname{TLC}\left(* 10^{3} / \mathrm{CC}\right)$ & $13(10.1,17.3)$ & $13(9,18.4)$ & 0.96 \\
\hline Initial Creatinine (mg/dl) & $0.9(0.7,1.2)$ & $0.9(0.7,1.2)$ & 0.87 \\
\hline $\mathrm{CRP}(\mathrm{mg} / \mathrm{L})$ & $120(48,183)$ & $77(37,130)$ & 0.03 \\
\hline Antibiotic use before referral & $67.8 \%$ & $70.5 \%$ & 0.69 \\
\hline Surgical management & $44(73.3 \%)$ & $121(66.5 \%)$ & 0.32 \\
\hline
\end{tabular}

ARA aortic root abscess, CKD chronic kidney disease, CRP C-reactive protein, DM diabetes mellitus, IE infective endocarditis, RHD rheumatic heart disease, $T L C$ total leucocytic count

group $(13.1 \%$ vs. $57.8 \%, p<0.001)$, while there is no significant difference between both groups regarding the combined mitral and aortic vegetations (8.2\% vs. $10.7 \%, p$ $=0.56)$.

Multivariate logistic regression analysis was done for the previously statistically significant data. Mechanical prosthesis, undetected organism, aortic vegetations, and paravalvular leakage were the most significant independent predictors of ARA, while the chances of ARA were lower with mitral valve vegetations as shown in Table 2.

Regarding complications, including in-hospital allcause mortality, there were no statistically significant differences between both groups, as shown in Table 3. Similar proportions of patients underwent surgery in both groups. There was no significant difference between surgically managed patients in both groups regarding in-hospital mortality and major complications, as shown in Table 4.

\section{Discussion}

In this study, we reviewed the clinical, laboratory, and echocardiographic data of patients with infective endocarditis associated with ARA. We reported several clinical (e.g., mechanical prosthesis), laboratory (e.g., higher 


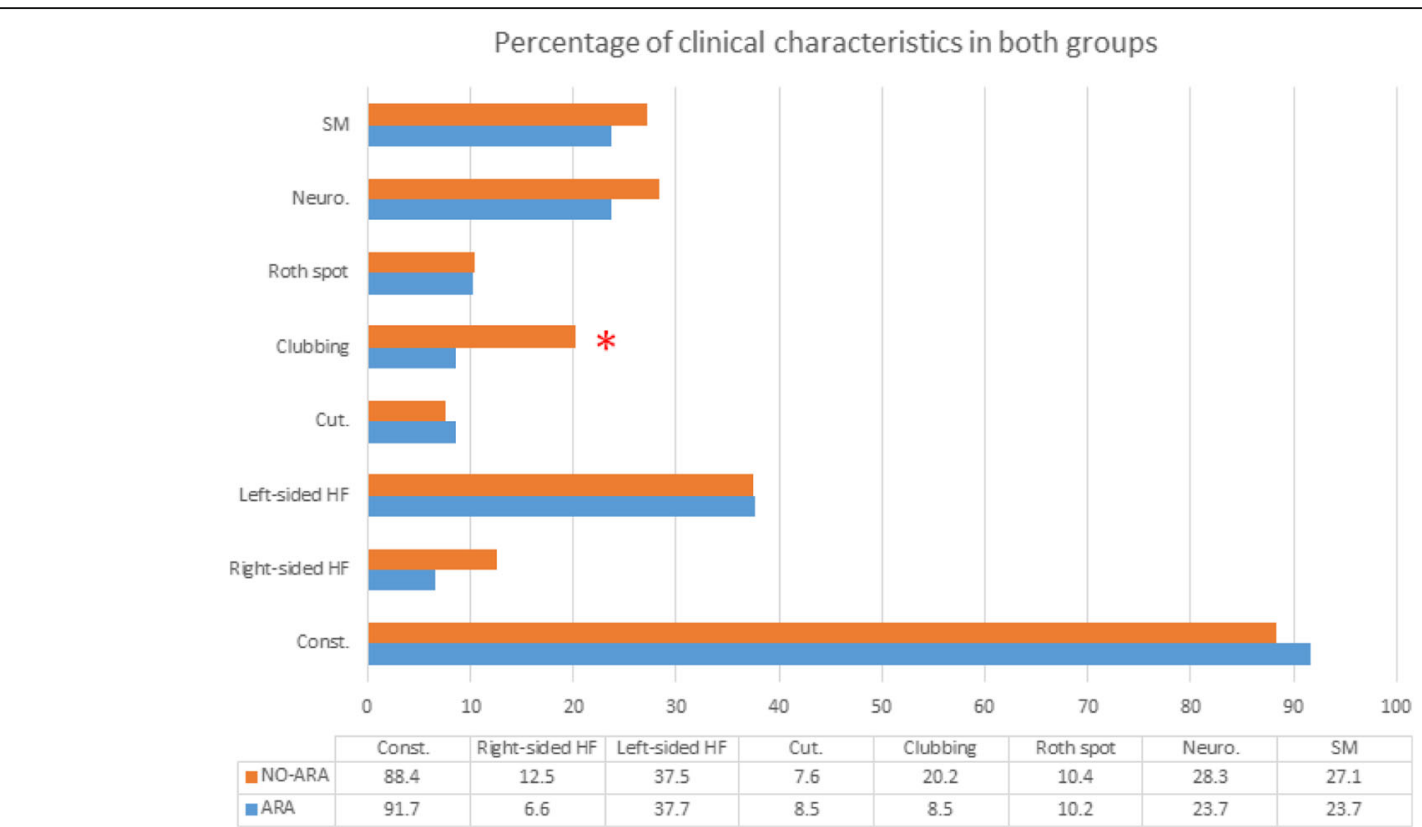

Fig. 2 Percentage of clinical findings in both groups. ARA, aortic root abscess; Const., constitutional manifestations; Cut., cutaneous manifestations; HF, heart failure; Neuro., neurological manifestations; NO-ARA, no aortic root abscess; SM, splenomegaly. ${ }^{*} \mathrm{p}=0.04$

CRP), and echocardiographic (e.g., aortic vegetations) variables that were significantly higher in ARA patients. The odds of ARA were higher in patients with a mechanical prosthesis, aortic vegetations, aortic paravalvular leakage, and undetected organisms and lower in those with mitral valve vegetations.

The prevalence of ARA was variable in past studies. An earlier report by John et al. detected ARA in 32 out of 50 patients with aortic IE (46\%) from 1982 to 1988 [6]. In Leung et al., ARA was detected in $32 \%$ of patients (11 out of 34 patients with aortic IE) in the period from 1989 to 1993 [17]. Anguera et al. identified ARA in 201 patients out of 2055 native aortic valve IE (9.8\%) in a retrospective analysis from 16 referral hospitals from 1992 to 2003 [18]. In the same issue, Anguera et al. reported ARA in 150 patients out of more than 872 prosthetic aortic valve IE (17\%) from the same registry [19]. Graupner et al. detected a higher prevalence of ARA in $37 \%$ of aortic IE patients (78 out of 211 patients from 1996 to 2000). In the TAVI era, prosthetic valve endocarditis was detected in 103 out of 4336 patients. Among these 103 patients, ARA was detected in 12 patients (11.9\%) [20]. Our study reported ARA in $21.4 \%$ of patients with left-sided IE and $40.1 \%$ of aortic valve IE. Late presentation and use of inappropriate antibiotics could explain the high percentage in this report, which reflects the current situation in Egypt.

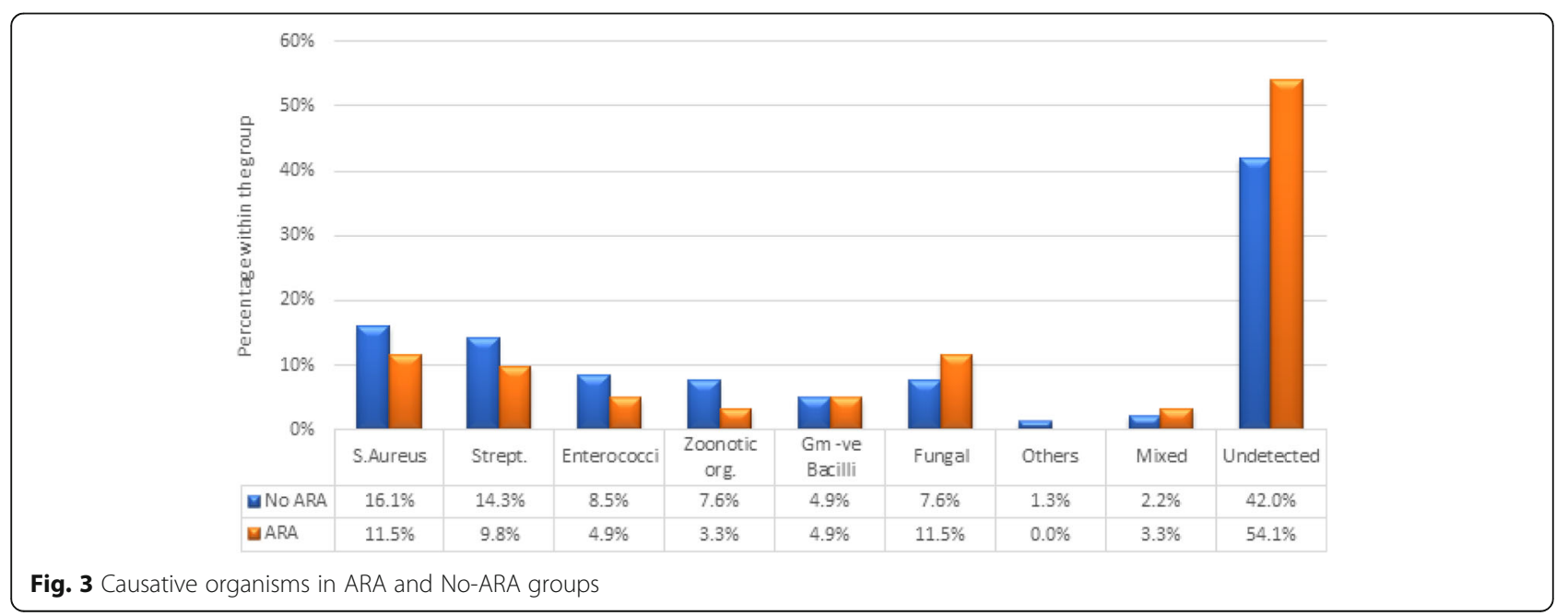




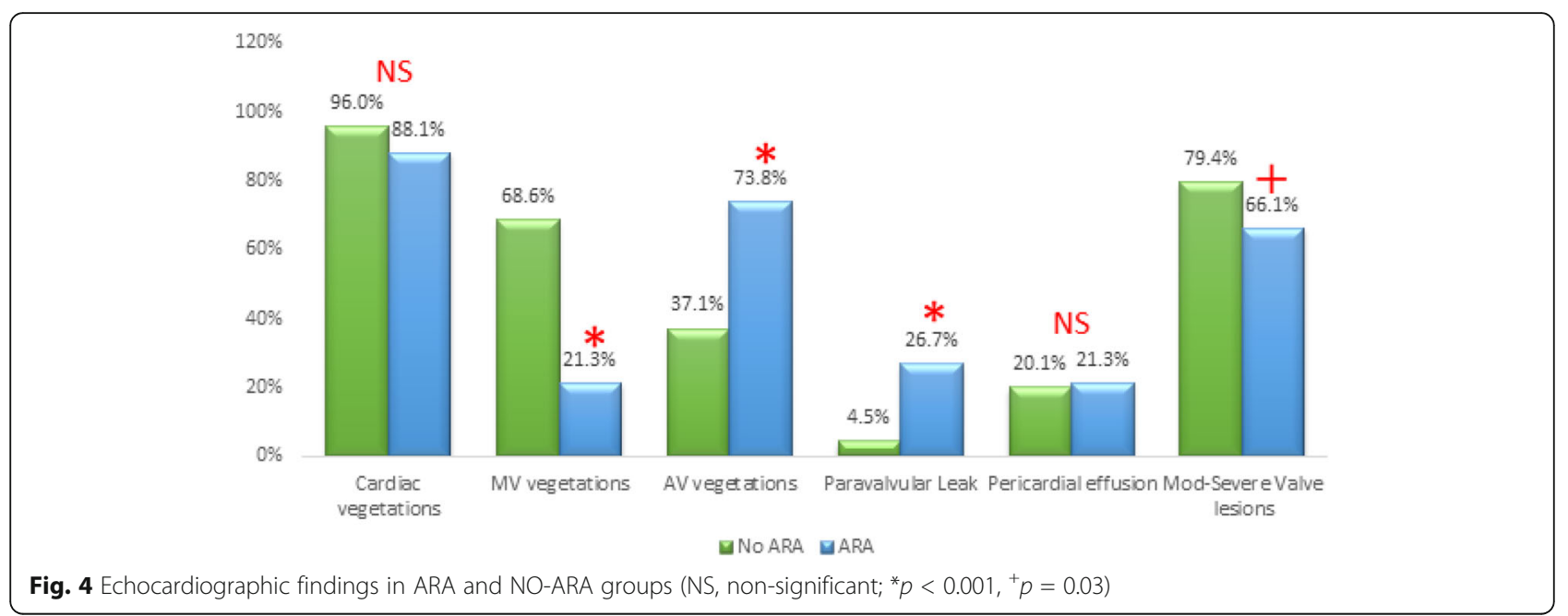

The median age of the study population was 31.5 years (IQR; 24, 42.2), which is much less than the worldwide reported age of ARA patients. In a recent meta-analysis, the age of ARA patients ranged from 37 to 62 years [21]. The young age of our patients reflects the type of the underlying heart disease in our study, being rheumatic or congenital heart disease in the majority of cases and degenerative heart disease in only $9.5 \%$ of cases. Age was not statistically different between both groups (ARA and NO-ARA groups), but the male gender was more common in the ARA group. Other reports for aortic root abscess also showed a trend of more incidence of ARA in male patients $[9,21]$.

Comorbid conditions such as diabetes mellitus and renal and hepatic diseases were similar in both groups. There was a trend of higher chronic steroid use in the NO-ARA group. Most of the patients on steroid therapy (11 patients) had mitral valve endocarditis, and only one patient had aortic and mitral valve endocarditis without abscess development. However, it is improper to assume any protective role of steroids from aortic root abscess.

We found that prosthetic mechanical valve and congenital heart disease were significantly higher in the ARA group. The prosthesis was found to be an independent predictor for ARA in previous studies [22]. The

Table 2 Logistic regression analysis for significant variables associated with ARA

\begin{tabular}{llll}
\hline & OR & $\mathbf{9 5 \% ~ C l}$ & $\boldsymbol{p}$ value \\
\hline Aortic PVL & 3.9 & $1.2-13.0$ & 0.03 \\
Mechanical prosthesis & 3.6 & $1.5-8.7$ & 0.005 \\
Aortic vegetations & 3.0 & $1.2-8.0$ & 0.02 \\
Undetected organism & 2.3 & $1.1-4.6$ & 0.02 \\
Mitral vegetations & 0.2 & $0.08-0.5$ & 0.001 \\
\hline
\end{tabular}

Cl confidence interval, $O R$ odds ratio, $P V L$ paravalvular leakage bicuspid aortic valve was the most common congenital heart disease in our study population and was significantly higher in the ARA group. Kiyota et al. [23] has shown that the bicuspid aortic valve is associated with an increased incidence of IE and ARA as compared with the trileaflet valve.

Clubbing was seen more in the NO-ARA group. This could be explained by the fact that clubbing needs some time to develop, which is not the case for IE with ARA, which is usually an aggressive, rapidly developing infection. CRP levels were higher in the ARA group. This finding could be explained by the more extensive damage and the more aggressive nature of ARA. However, we did not find any previous reports describing the above two findings.

There was an increased likelihood of microorganisms' un-detection in our study population (i.e., negative blood cultures and serology) that may be attributed to increased use of antibiotics before referral. This microorganism un-detection was numerically higher in the ARA group compared with the No-ARA group $(54.1 \%$

Table 3 Major complications in ARA and NO-ARA groups, N (\%)

\begin{tabular}{llll}
\hline Event & ARA & NO-ARA & $\boldsymbol{p}$ value \\
\hline In-hospital mortality & $22(36.1 \%)$ & $67(29.9 \%)$ & 0.36 \\
Heart failure Fc III/IV & $28(45.9 \%)$ & $113(50.4 \%)$ & 0.53 \\
Sepsis & $15(24.6 \%)$ & $39(17.4 \%)$ & 0.21 \\
Peripheral embolization & $22(36.1 \%)$ & $74(33.0 \%)$ & 0.66 \\
Splenic infarction & $7(11.5 \%)$ & $35(15.6 \%)$ & 0.42 \\
Mycotic aneurysms & $6(10.0 \%)$ & $17(7.7 \%)$ & 0.60 \\
Cerebral embolization & $18(29.5 \%)$ & $66(29.5 \%)$ & 0.995 \\
All embolization & $32(52.2 \%)$ & $121(54.0 \%)$ & 0.83 \\
Acute kidney injury & $22(36.1 \%)$ & $64(28.6 \%)$ & 0.26 \\
Dialysis & $2(3.4 \%)$ & $11(5.0 \%)$ & 0.999 \\
\hline
\end{tabular}


Table 4 In-hospital mortality and major complications in surgically treated patients in both groups, $N(\%)$

\begin{tabular}{llll}
\hline & ARA $(\boldsymbol{N}=\mathbf{4 4})$ & NO-ARA $(\boldsymbol{N}=\mathbf{1 2 1})$ & $\boldsymbol{p}$ value \\
\hline In-hospital mortality & $13(29.5 \%)$ & $30(24.8 \%)$ & 0.54 \\
Major complications & $31(70.5 \%)$ & $86(71.1 \%)$ & 0.94 \\
\hline
\end{tabular}

vs. $42 \%, p=0.09)$. On the other hand, the detected microorganisms were not different between both groups. Staphylococcus aureus and fungal infections represent the most commonly detected organisms in the ARA group (each occurred in $11.5 \%$ of ARA patients). Staphylococcus aureus was commonly found in ARA patients in previous studies [24, 25].

Regarding the complications, there was no statistically significant difference between both groups, including allcause in-hospital mortality. These results contrast previous data that showed a worse outcome of IE complicated with aortic root abscess [26, 27]. The relatively late presentation and delayed surgical intervention in both groups could be the cause of the comparable outcome.

In our study, the ARA group showed more aortic valve vegetations and less mitral valve vegetations. This finding seems reasonable in a study of aortic root abscess and not mitral ring abscess. However, this may raise a question regarding the well-known site for aortic root abscess, which is the aortomitral continuity. Forteza et al. operated upon 26 patients with aortic valve IE and intervalvular fibrous body abscess representing $10.6 \%$ of the patients with aortic valve IE [28]. Our study suggests that the spread from aortic valve endocarditis is the original site of the ARA that can extend into aortomitral continuity, rather than perivalvular infection in mitral valve endocarditis.

The paravalvular leak was significantly higher in the ARA group. The paravalvular leak is a common finding in prosthetic valve endocarditis. Anguera et al. detected moderate to severe aortic paravalvular leak in $45 \%$ of patients with prosthetic valve IE. Prosthetic valve IE usually begins as periannulitis and then spreads to adjacent tissues causing an abscess and can lead to a paravalvular leak [19]. The presence of moderate to severe regurgitant valve lesion was found to be lower in the ARA as compared to the NO-ARA group. This result can be explained in two aspects. First, all implanted prostheses in our study population were mechanical, where paravalvular leakage is much more common than transvalvular regurgitation. Second, perhaps the original site of the infection in ARA is more eccentric at the annulus more than the valve itself, favoring the spread of infection to adjacent tissues causing periannular complications rather than destroying the valve itself.
Multivariate analysis of the above variables showed that the presence of mechanical prosthesis and paravalvular leakage were the most independent predictors of ARA (OR 3.7 and 3.9, respectively). The presence of mechanical prosthesis also seems to be associated with an increased risk of development of ARA. This result highlights the importance of appropriate perioperative sterilization and disinfection, as well as the necessity of proper hygiene in patients with prosthetic valves. The presence of paravalvular leakage of any degree in the presence of clinical suspicion should be alarming to the possibility of ARA. All required investigations such as transesophageal echocardiography and CT aortography should be done to exclude ARA. Other independent predictors were aortic valve vegetations and undetected organisms. Both variables suggest the presence of the aggressive nature of infection that leads to this severe annular complication. ARA was less seen in the presence of mitral valve vegetations.

Studies reporting the predictors of ARA are scarce and relatively old. Omari et al. reported aortic valve infection and intravenous drug abuse as the most independent predictors of ARA in patients with native aortic valve IE [24]. Later, Blumberg et al. identified a new atrioventricular or bundle branch block as the only significant correlation [29]. In another study, the most common risk factors for paravalvular infection were prosthetic valve, aortic valve infection, and coagulase-negative staphylococci [30]. We could not find any recent studies highlighting the ARA predictors.

The latest trials of ARA focused on the outcome of surgical procedures. A meta-analysis by Chen et al. [21] reviewed seven surgical trials of ARA, comparing the results of aortic root replacement vs. aortic valve replacement. There was no difference between both procedures on 30-day follow-up; however, aortic root replacement was associated with a $50 \%$ reduction of the rate of reoperation on 1-year follow-up. Kirali et al. [31] showed surgical outcomes in 27 patients with ARA. The mean duration of follow-up was $6.8 \pm 3.7$ years. In-hospital mortality was $22.2 \%$, which was lower than in-hospital mortality reported in our study (36.1\%). Mean 1-, 5-, and 10-year survival were $70.2 \%, 62.2 \%$, and $59.2 \%$, respectively. Sultan et al. [32] studied the use of aortic homograft in 138 ARA patients with relatively not high surgical mortality (12.3\%). However, 5-year mortality was again high (43\%). Yang et al. [33] showed similar results in 179 patients with an operative mortality of $8.4 \%$ and 10 -year mortality of $59 \%$. So, despite the good immediate surgical outcome in ARA patients, this complication carries an increased risk of mortality on long-term follow-up.

There are some limitations to our study. First, it was an observational study, being limited by the lack of local resources and expertise. Second, underlying cardiovascular 
conditions, time to presentation, the causative microorganisms, and antibiotic regimen protocols may differ between different countries. Third, the relatively small number of ARA patients is considered a limitation. However, the majority of previous studies reported their results based on a similar number of patients due to the slow recruitment of ARA in clinical studies. Finally, the significant variables by multivariate analysis in our study showed a wide confidence interval. The leading cause of this wide CI was the limited sample size. The confidence intervals of odds ratios were also wide in the previous ARA studies. In Leontyev et al., one of the largest studies of surgical treatment of ARA with 172 patients, all independent predictors of mortality showed wide CI (e.g., sepsis had OR 3.6 with $95 \%$ CI 1.2-10.7) [34]. Increasing sample size could lead to a narrower confidence interval; however, the recruitment of a large number of ARA patients into a clinical study still represents a challenge.

\section{Conclusion}

Our study showed that ARA represents a common complication in patients with left-sided IE. Mechanical prosthesis, aortic paravalvular leakage, aortic vegetations, and undetected organisms were the most independent variables associated with ARA. On the other hand, the mitral valve IE was significantly lower in patients with ARA. The presence of these variables in the context of IE should be alarming to the increased risk of ARA, and the clinician should use different imaging modalities (TEE, CT aortography, PET scan) to exclude ARA as appropriate. We recommend future multicenter research to elucidate the predictors of ARA and to evaluate the long-term outcome in ARA patients.

\section{Abbreviations}

ARA: Aortic root abscess; Cl: Confidence interval; CKD: Chronic kidney disease; CRP: C-reactive protein; DM: Diabetes mellitus; HF: Heart failure; IE: Infective endocarditis; NO-ARA: No aortic root abscess; NYHA Fc: New York Heart Association functional class; PVL: Paravalvular leak; OR: Odds ratio; RHD: Rheumatic heart disease; SOFA: Sepsis-related Organ Failure Assessment; TEE: Transesophageal echocardiography; TLC: Total leukocytic count; TTE: Transthoracic echocardiography

\section{Acknowledgements}

The authors would like to thank Dr. Dina Osama for doing the statistical analysis for this study.

\section{Authors' contributions}

Dr. KM reviewed the literature, revised and modified the statistical analysis, and wrote the manuscript. Dr. MM is the head of the infective endocarditis project in Kasr ElAiny Hospital, Cairo University, and this work was her idea. Dr. HK participated in the study design. Dr. TH participated in the data collection, management, and follow-up of recruited patients. All authors read and approved the final manuscript.

\section{Funding}

None.

\section{Availability of data and materials}

The dataset supporting the results and conclusions of this article will be available from the corresponding author on request.

\section{Ethics approval and consent to participate}

This research involved human subjects and was performed in accordance with the Declaration of Helsinki and approved by Cairo University Ethical Review Committee (Reference number is not available). Written informed consent was obtained from all patients that included agreement on the collection of his/her data.

\section{Consent for publication}

Not applicable,

\section{Competing interests}

The authors declare that they have no competing interests.

Received: 11 July 2020 Accepted: 15 September 2020

Published online: 29 September 2020

\section{References}

1. Bin AAA, Baddour LM, Erwin PJ, Hoen B, Chu VH, Mensah GA et al (2014) Global and regional burden of infective endocarditis, 1990-2010: a systematic review of the literature. Glob Heart 9(1):131-143

2. Habib G, Lancellotti P, Antunes MJ, Bongiorni MG, Casalta J-P, Del Zotti F et al (2015) 2015 ESC guidelines for the management of infective endocarditis: the task force for the management of infective endocarditis of the European Society of Cardiology (ESC) endorsed by: European Association for Cardio-Thoracic Surgery (EACTS), the European A. Eur Heart J 36(44):3075-3128

3. Heldman AW, Hartert TV, Ray SC, Daoud EG, Kowalski TE, Pompili VJ et al (1996) Oral antibiotic treatment of right-sided staphylococcal endocarditis in injection drug users: prospective randomized comparison with parenteral therapy. Am J Med 101(1):68-76

4. Stamboulian D, Bonvehi P, Arevalo C, Bologna R, Cassetti I, Scilingo V, et al. Antibiotic management of outpatients with endocarditis due to penicillinsusceptible streptococci. Rev Infect Dis. 1991;13(Supplement_2):S160-3.

5. Iversen K, Ihlemann N, Gill SU, Madsen T, Elming H, Jensen KT et al (2019) Partial oral versus intravenous antibiotic treatment of endocarditis. N Engl J Med 380(5):415-424

6. John RM, Pugsley W, Treasure T, Sturridge MF, Swanton RH (1991) Aortic root complications of infective endocarditis-influence on surgical outcome. Eur Heart J 12(2):241-248

7. Thuny F, Beurtheret S, Mancini J, Gariboldi V, Casalta J-P, Riberi A et al (2011) The timing of surgery influences mortality and morbidity in adults with severe complicated infective endocarditis: a propensity analysis. Eur Heart J 32(16):2027-2033

8. Habib G, Avierinos J-F, Thuny F (2007) Aortic valve endocarditis: is there an optimal surgical timing? Curr Opin Cardiol 22(2):77-83

9. Choussat R, Thomas D, Isnard R, Michel P-L, lung B, Hanania G et al (1999) Perivalvular abscesses associated with endocarditis: clinical features and prognostic factors of overall survival in a series of 233 cases. Eur Heart J 20(3):232-241

10. Li JS, Sexton DJ, Mick N, Nettles R, Fowler VG Jr, Ryan T et al (2000) Proposed modifications to the Duke criteria for the diagnosis of infective endocarditis. Clin Infect Dis 30(4):633-638

11. La Scola B, Raoult D (2009) Direct identification of bacteria in positive blood culture bottles by matrix-assisted laser desorption ionisation time-of-flight mass spectrometry. PLoS One 4:11

12. Habib G, (France), Badano L, (Italy), Tribouilloy C, (France), et al. Recommendations for the practice of echocardiography in infective endocarditis. Eur J Echocardiogr 2010;11(2):202-219.

13. Hahn RT, Abraham T, Adams MS, Bruce CJ, Glas KE, Lang RM et al (2013) Guidelines for performing a comprehensive transesophageal echocardiographic examination: recommendations from the American Society of Echocardiography and the Society of Cardiovascular Anesthesiologists. J Am Soc Echocardiogr 26(9):921-964

14. Mügge A, Daniel WG, Frank G, Lichtlen PR (1989) Echocardiography in infective endocarditis: reassessment of prognostic implications of vegetation size determined by the transthoracic and the transesophageal approach. J Am Coll Cardiol 14(3):631-638

15. Vincent J-L, Moreno R, Takala J, Willatts S, De Mendonça A, Bruining H, et al. The SOFA (Sepsis-related Organ Failure Assessment) score to describe organ dysfunction/failure. Springer-Verlag; 1996. 
16. Kdigo AKI, Work Group (2012) KDIGO clinical practice guideline for acute kidney injury. Kidney Int Suppl 2(1):1-138

17. Leung DY, Cranney GB, Hopkins AP, Walsh WF. Role of transoesophageal echocardiography in the diagnosis and management of aortic root abscess. Br Heart J [Internet]. 1994 1;72(2):175 LP - 181. Available from: http://heart. bmi.com/content/72/2/175.abstract

18. Anguera I, Miro JM, Evangelista A, Cabell CH, San Roman JA, Vilacosta I et al (2006) Periannular complications in infective endocarditis involving native aortic valves. Am J Cardiol 98(9):1254-1260

19. Anguera I, Miro JM, San Roman JA, de Alarcon A, Anguita M, Almirante B et al (2006) Periannular complications in infective endocarditis involving prosthetic aortic valves. Am J Cardiol 98(9):1261-1268

20. Bjursten H, Rasmussen M, Nozohoor S, Götberg M, Olaison L, Rück A, et al. Infective endocarditis after transcatheter aortic valve implantation: a nationwide study. Eur Heart J [Internet]. 2019 Aug 21:40(39):3263-9. Available from: https://doi.org/10.1093/eurhearti/ehz588

21. Chen G-J, Lo W-C, Tseng H-W, Pan S-C, Chen Y-S, Chang S-C. Outcome of surgical intervention for aortic root abscess: a meta-analysis. Eur J CardioThoracic Surg [Internet]. 2017 Dec 2;53(4):807-14. Available from: https://doi. org/10.1093/ejcts/ezx421

22. Graupner C, Vilacosta I, SanRomán J, Ronderos R, Sarriá C, Fernández C et al (2002) Periannular extension of infective endocarditis. J Am Coll Cardiol 39(7):1204-1211

23. Kiyota Y, Della Corte A, Montiero Vieira V, Habchi K, Huang C-C, Della Ratta $\mathrm{EE}$, et al. Risk and outcomes of aortic valve endocarditis among patients with bicuspid and tricuspid aortic valves. Open Hear [Internet]. 2017 1:4(1): openhrt-2016-000545. Available from: http://openheart.bmj.com/ content/4/1/openhrt-2016-000545.abstract

24. Omari B, Shapiro S, Ginzton L, Robertson JM, Ward J, Nelson RJ et al (1989) Predictive risk factors for periannular extension of native valve endocarditis: clinical and echocardiographic analyses. Chest. 96(6):1273-1279

25. San Román JA, Vilacosta I, Sarriá C, de la Fuente L, Sanz O, Vega JL et al (1999) Clinical course, microbiologic profile, and diagnosis of periannular complications in prosthetic valve endocarditis. Am J Cardiol 83(7):1075-1079

26. Lalani T, Chu VH, Park LP, Cecchi E, Corey GR, Durante-Mangoni E et al (2013) In-hospital and 1-year mortality in patients undergoing early surgery for prosthetic valve endocarditis. JAMA Intern Med 173(16):1495-1504

27. Aksoy O, Sexton DJ, Wang A, Pappas PA, Kourany W, Chu V et al (2007) Early surgery in patients with infective endocarditis: a propensity score analysis. Clin Infect Dis 44(3):364-372

28. Forteza A, Centeno J, Ospina V, Lunar IG, Sánchez V, Pérez E et al (2015) Outcomes in aortic and mitral valve replacement with intervalvular fibrous body reconstruction. Ann Thorac Surg 99(3):838-845

29. Blumberg EA, Karalis DA, Chandrasekaran K, Wahl JM, Vilaro J, Covalesky VA et al (1995) Endocarditis-associated paravalvular abscesses: do clinical parameters predict the presence of abscess? Chest. 107(4):898-903

30. Chan K-L (2002) Early clinical course and long-term outcome of patients with infective endocarditis complicated by perivalvular abscess. Cmaj. 167(1):19-24

31. Kirali K, Sarikaya S, Ozen Y, Sacli H, Basaran E, Yerlikhan OA et al (2016) Surgery for aortic root abscess: a 15-year experience. Texas Hear Inst J [Internet] 43(1): 20-28 Available from: https://pubmed.ncbi.nlm.nih.gov/27047281

32. Sultan I, Bianco V, Kilic A, Chu D, Navid F, Gleason TG. Aortic root replacement with cryopreserved homograft for infective endocarditis in the modern North American opioid epidemic. J Thorac Cardiovasc Surg [Internet]. 2019;157(1):45-50. Available from: http://www.sciencedirect.com/ science/article/pii/S0022522318314739

33. Yang B, Caceres J, Farhat L, Le T, Brown B, St. Pierre E, et al. Root abscess in the setting of infectious endocarditis: Short- and long-term outcomes. J Thorac Cardiovasc Surg [Internet]. 2020; Available from: http://www. sciencedirect.com/science/article/pii/S002252232030814X

34. Leontyev S, Borger MA, Modi P, Lehmann S, Seeburger J, Doenst T, et al. Surgical management of aortic root abscess: a 13-year experience in 172 patients with 100\% follow-up. J Thorac Cardiovasc Surg [Internet]. 2012; 143(2):332-7. Available from: http://www.sciencedirect.com/science/article/ pii/S0022522311005708

\section{Publisher's Note}

Springer Nature remains neutral with regard to jurisdictional claims in published maps and institutional affiliations.

\section{Submit your manuscript to a SpringerOpen ${ }^{\circ}$ journal and benefit from:}

- Convenient online submission

- Rigorous peer review

- Open access: articles freely available online

High visibility within the field

- Retaining the copyright to your article

Submit your next manuscript at $\boldsymbol{\nabla}$ springeropen.com 